\title{
The Vibrations Study of DAMMAR Based Composite Bars Reinforced with Natural Fibers by Using a New Euler - Bernoulli Theory
}

\author{
ALEXANDRU BOLCU ${ }^{1}$, NICOLAE DUMITRU ${ }^{1}$, ION CIUCA ${ }^{2}$, MARIUS MARINEL STANESCU ${ }^{3 *}$, DUMITRU BOLCU ${ }^{1}$ \\ ${ }^{1}$ University of Craiova, Faculty of Mechanics, 165 Calea Bucuresti, 200620, Craiova, Romania \\ ${ }^{2}$ Politehnica University of Bucharest, Faculty of Engineering and Materials Science, 313 Splaiul Independentei, 060042, Bucharest, \\ Romania \\ ${ }^{3}$ University of Craiova, Department of Applied Mathematics, 13 A.I.Cuza Str., 200396, Craiova, Romania
}

\begin{abstract}
In the paper it is presented a new Euler - Bernoulli theory based on an assymetrical distribution of strains towards the median plane, the area subjected to compression has a transversal stretching, while the area subjected to tensile has a transversal contraction. This theory takes into account the transversal contraction factors and consequently the eigenpulsations of bars vibrations with rectangular section depend on the ratio between the bars width and thickness. This theory is experimentally verified for Dammar based composite bars reinforced with cotton, flax, silk and hemp fibers. For the considered bars, we have experimentally determined the eigen frequencies and the damping factor values.
\end{abstract}

Keywords: composite bar, bar eigenpulsations, Euler-Bernoulli theory

The composite bars vibrations can be analyzed through many theories which especially differ by including or neglecting the angular deformations effects, respectively the rotation intertia. The composite bars vibrations elementary study relies on Euler - Bernoully hypothesis in which a straight line normal on the median plane before deformation, remains straight and normal on the median surface during deformation. Another theory called also the First - order Shear Deformation Theory (FSDT) has been developed in [1] and detailed in [2]. This theory relies on a linear distribution of the shear stresses and it requests a correction factor. In this theory, a line normal on the median plane before deformation, remains straight without keeping, during the deformation, the perpendicularity on the median plane. In the case of bars vibration, this theory was firstly used by Timoshenko [3].

The exact theories of anisotropic plates and bars rely on a non-linear distribution of shear stresses along the thickness because of some longitudinal deformations that nonlinear vary of the bar thickness. The functions that give the longitudinal deformations on the bars thickness are presented in [4-10]. Shear theories based on trigonometrical expansions which fulfill the bar surfaces conditions are presented in [11-13]. The way in which the nonuniformities and the reinforcement random distribution influence the mechanical behaviour of composite materials is presented in [14-15]. All these theories do not take into account deformations on the bars width and that is why it is considered that this parameter does not influence the eingenfrequencies of the bars vibrations. A theory that takes into account the bars deformation on the width and which presents the influence over the vibration eigenmodes is presented in [16],

In the last years, the interest of using natural fibers and resins for creating composite materials has increased. The usage of natural fibers as reinforcement has many advantages, such as: relatively low cost, abundance in nature, low weight, less damages to manufacturing equipments, good surface finishing for molded products (compared to the composites glass fiber based), good relative mechanical properties. Various articles [17-24] present the properties of natural fibers and resins. From the vegetable resins, the most used are Sandarac, Copal and Dammar, from the fossils resins the amber can be remembered and the Shellac, from the animal ones. In [25] the mechanical behaviour of some composite materials that have a Dammar based resin is studied. As reinforcing materials, there were used flax, silk, cotton and hemp fibers. There were determined the main mechanical characteristics for the used resin butalso for the composite materials obtained by reinforcing this resin with the told fibers. In [16], the bars vibrations with rectangular section made from these materials having one of two exterior layers reinforced with glass fibers are studied. The possibilities of these materials usage combined with intelligent ones are presented in [26].

\section{Theoretical background}

A bar with constant rectangular shape section is considered with $2 b$ width and $2 h$ thickness (fig. 1 ).

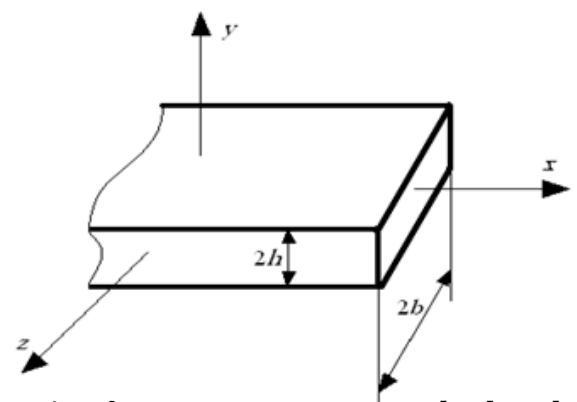

Fig. 1.

A reference system is attached to this bar, in this way: -the $x$ axis represents the longitudinal symmetry axis of the bar;

-the $y$ axis is focused on the bar thickness;

-the $z$ axis is focused on the width direction (fig. 1).

During the vibrations, the bar points will have displacements along all three axes:

-displacement along the $x$ axis:

$$
w_{x}=w_{x}(x ; y ; z ; t) \text {; }
$$

-displacement along they axis:

$$
w_{y}=w_{y}(x ; y ; z ; t) \text {; }
$$

-displacement along the $z$ axis: 


$$
w_{z}=w_{z}(x, y ; z ; t) .
$$

If only the transversal vibrations are taken into account, neglecting the longitudinal and torque ones, the functions which characterizes the displacements over the three axes must fulfill the next conditions:

-the $w_{x}$ displacement must be an even function in the $z$ variable and uneven in $y$,

-the $w_{y}$ displacement must be an even function in both $z$ and $y$ varriables,

-the $w$ displacement must be be an uneven function in both $z$ and $y$ variables,

In order to fulfill these conditions, the next state of displacements is considered:

$$
\begin{aligned}
& w_{x}=u_{x}(x ; y ; t)+z^{2} v_{x}(x ; y ; t) ; \\
& w_{y}=u_{y}(x ; y ; t)+z^{2} v_{y}(x ; y ; t) ; \\
& w_{z}=z \theta(x ; y ; t)+\frac{z^{3}}{b^{2}} \varphi(x ; y ; t) .
\end{aligned}
$$

The parts of deformations tensor are:

$$
\begin{gathered}
\varepsilon_{x x}=\frac{\partial u_{x}}{\partial x}+z^{2} \frac{\partial v_{x}}{\partial x}, \\
\varepsilon_{y y}=\frac{\partial u_{y}}{\partial y}+z^{2} \frac{\partial v_{y}}{\partial y}, \\
\varepsilon_{z z}=\theta+3 \frac{z^{2}}{b^{2}} \varphi, \\
\gamma_{x y}=\frac{\partial u_{x}}{\partial y}+\frac{\partial u_{y}}{\partial x}+z^{2}\left(\frac{\partial v_{x}}{\partial y}+\frac{\partial v_{y}}{\partial x}\right), \\
\gamma_{x z}=z\left(2 v_{x}+\frac{\partial \theta}{\partial x}\right)+\frac{z^{3}}{b^{2}} \frac{\partial \varphi}{\partial x}, \\
\gamma_{y z}=z\left(2 v_{y}+\frac{\partial \theta}{\partial y}\right)+\frac{z^{3}}{b^{2}} \frac{\partial \varphi}{\partial y} .
\end{gathered}
$$

By considering that the bar materials has a liner-elastical behaviour, the stress tensor parts, calculated with Hooke relations are:

$$
\begin{gathered}
\sigma_{x x}=E_{x x} \frac{\partial u_{x}}{\partial x}+E_{x y} \frac{\partial u_{y}}{\partial y}+E_{x z} \theta+z^{2}\left(E_{x x} \frac{\partial v_{x}}{\partial x}+E_{x y} \frac{\partial v_{y}}{\partial y}+\frac{3}{b^{2}} E_{x z} \varphi\right), \\
\sigma_{y y}=E_{y x} \frac{\partial u_{x}}{\partial x}+E_{y y} \frac{\partial u_{y}}{\partial y}+E_{y z} \theta+z^{2}\left(E_{y x} \frac{\partial v_{x}}{\partial x}+E_{y y} \frac{\partial v_{y}}{\partial y}+\frac{3}{b^{2}} E_{y z} \varphi\right), \\
\sigma_{z z}=E_{z x} \frac{\partial u_{x}}{\partial x}+E_{z y} \frac{\partial u_{y}}{\partial y}+E_{z z} \theta+z^{2}\left(E_{z x} \frac{\partial v_{x}}{\partial x}+E_{z y} \frac{\partial v_{y}}{\partial y}+\frac{3}{b^{2}} E_{z z} \varphi\right), \\
\sigma_{x y}=G_{x y}\left[\frac{\partial u_{x}}{\partial y}+\frac{\partial u_{y}}{\partial x}+z^{2}\left(\frac{\partial v_{x}}{\partial y}+\frac{\partial v_{y}}{\partial x}\right)\right], \\
\sigma_{x z}=G_{x z}\left[z\left(2 v_{x}+\frac{\partial \theta}{\partial x}\right)+\frac{z^{3}}{b^{2}} \frac{\partial \varphi}{\partial x}\right] \\
\sigma_{y z}=G_{y z}\left[z\left(2 v_{y}+\frac{\partial \theta}{\partial y}\right)+\frac{z^{3}}{b^{2}} \frac{\partial \varphi}{\partial y}\right],
\end{gathered}
$$

where $E_{x x^{\prime}} E_{y^{\prime}}, E_{z z^{\prime}} E_{x y}=E_{y x^{\prime}} E_{z x}=E_{z x^{\prime}} E_{l y z}=E_{z y^{\prime}} G_{x y} G_{x z^{\prime}} G_{y z}$ are the elastic factors.

By considering that on the exterior bar surface no forces act, the normal and shear stresses on these surfaces are zero. So, for $z= \pm b$ and $y= \pm h$, we have:
- for $z= \pm b$ :

$$
\begin{aligned}
& \sigma_{x z}(x, y ; \pm b ; t)=0, \\
& \sigma_{y z}(x ; y ; \pm b ; t)=0, \\
& \sigma_{z z}(x ; y ; \pm b ; t)=0,
\end{aligned}
$$

-for $y= \pm h$ :

$$
\begin{aligned}
& \sigma_{x y}(x, \pm h ; z ; t)=0, \\
& \sigma_{y y}(x ; \pm h ; z ; t)=0, \\
& \sigma_{z y}(x ; \pm h ; z ; t)=0 .
\end{aligned}
$$

The functions that characterize the bar deformations are considered to have the next form:

$$
\begin{aligned}
& u_{x}=w^{\prime}(x, t) u(y)+w^{\prime \prime}(x, t) a(y), \\
& u_{y}=w(x ; t) v(y)+w^{\prime \prime}(x ; t) b(y), \\
& \theta=w(x, t) f(y)+w^{\prime \prime}(x, t) p(y), \\
& \varphi=w(x, t) g(y)+w^{\prime \prime}(x, t) q(y) .
\end{aligned}
$$

If the conditions are inserted:

$$
\begin{aligned}
& v(0)=1, \\
& b(0)=0,
\end{aligned}
$$

then $w(x ; t)$ is the transversal displacement of the bar medium fiber (for $y=0$ and $z=0$ ). We have marked with $w^{\prime}(x ; t)$ the derivative in relation with $x$ variable of $w(x ; t)$ function.

Function $u(y), a(y), f(y), g(y), p(y)$, and $q(y)$ are uneven in $y$ variable, and the functions $v(y)$ and $b(y)$ are even in this variable.

The conditions on the bar exterior surface are customized for these functions. The next conditions are obtained:

$$
\begin{gathered}
E_{z z}\left[a(y)-\frac{b^{2}}{2}(p(y)+q(y))\right]=0, \\
E_{z z} u(y)+E_{z y} b^{\prime}(y)+E_{z z}(p(y)+3 q(y))- \\
-\frac{b^{2}}{2} E_{z z}(f(y)+g(y))-\frac{b^{2}}{2} E_{z y}\left(p^{\prime \prime}(y)+q^{\prime \prime}(y)\right)=0, \\
E_{z y} y^{\prime}(y)+E_{z z}(f(y)+3 g(y))-\frac{b^{2}}{2} E_{z y}\left(f^{\prime \prime}(y)+g^{\prime \prime}(y)\right)=0 . \\
u^{\prime}(h)+v(h)=0, \\
a^{\prime}(h)+b(h)=0 . \\
f^{\prime}(h)+g^{\prime}(h)=0, \\
p^{\prime}(h)+q^{\prime}(h)=0 . \\
E_{y x} a(h)=0, \\
E_{y x u} u(h)+E_{y y} b^{\prime}(h)+E_{y z} p(h)=0, \\
E_{y x}(p(h)+q(h))=0, \\
E_{y x}(f(h)+g(h))+E_{y y}\left(p^{\prime \prime}(h)+q^{\prime \prime}(h)\right)-\frac{6}{b^{2}} E_{y z} q(h)=0, \\
E_{y y}\left(f^{\prime \prime}(h)+g^{\prime \prime}(h)\right)-\frac{6}{b^{2}} E_{y z} g(h)=0 . \\
g^{\prime}(h)=0 \\
q^{\prime}(h)=0 .
\end{gathered}
$$

For the inertia force on the bar length to be proportional with $w(x ; t)$, and thebending moment to be proportional with $w^{\prime \prime}(x ; t)$ the next condition must be fulfiled: 


$$
\begin{aligned}
& \int_{0}^{h} b(y) d y=0, \\
& \int_{0}^{h} y \cdot v^{\prime}(y) d y=0, \\
& \int_{0}^{h} y(f(y)+g(y)) d y=0, \\
& \int_{0}^{h} y(p(y)+q(y)) d y=0 .
\end{aligned}
$$

For the displacement along the $x$ axis, for the bar lower and higher surfaces, to coincide with the one from the Euler-Bernoulli theory, the condition is added:

$$
u(h)=-h \text {. }
$$

The previous functions are considered with the next form:

$$
\begin{aligned}
& g(y)=\sum_{k=1} \frac{g_{2 k-1}}{h^{2 k-1}} \cdot y^{2 k-1}, \\
& f(y)=\sum_{k=1} \frac{f_{2 k-1}}{h^{2 k-1}} \cdot y^{2 k-1}, \\
& p(y)=\sum_{k=1} \frac{p_{2 k-1}}{h^{2 k-1}} \cdot y^{2 k-1}, \\
& q(y)=\sum_{k=1} \frac{q_{2 k-1}}{h^{2 k-1}} \cdot y^{2 k-1}, \\
& v(y)=1+\sum_{k=1} \frac{v_{2 k}}{h^{2 k-1}} \cdot y^{2 k}, \\
& b(y)=\sum_{k=1} \frac{b_{2 k}}{h^{2 k-1}} \cdot y^{2 k} .
\end{aligned}
$$

If $E_{z x}=0$ is considered, the functions values on the superior bar surface are:

$$
\begin{aligned}
& g(h)=\frac{3 h}{b^{2}} \cdot \frac{E_{z y} E_{y z}}{E_{z y} E_{y z}+2 E_{y y} E_{z z}}, \\
& b^{\prime}(h)=-\frac{E_{y x}}{E_{y y}}\left(\frac{b^{2}}{3} g(h)-h\right), \\
& q(h)=-\frac{b^{2}}{3} \frac{E_{y x}}{E_{y z}} g(h), \\
& p(h)=-q(h), \\
& f(h)=-3 g(h), \\
& v(h)=1+\frac{3 E_{y z}}{E_{y y}} \cdot \frac{h g(h)}{16} .
\end{aligned}
$$

For the $b(y)$ function the $b^{\prime}(h)$ was given, because $b(h)=0$.

By keeping the first four terms from the relation (42) sums, the next factors are obtained: -for $b(y)$ function

$$
\begin{aligned}
& b_{2}=\frac{9}{8} b^{\prime}(h) ; \\
& b_{4}=-5 b^{\prime}(h) ; \\
& b_{6}=\frac{49}{8} b^{\prime}(h) ; \\
& b_{8}=-\frac{9}{4} b^{\prime}(h) ;
\end{aligned}
$$

-for $q(y)$ function

$$
\begin{aligned}
& q_{1}=-\frac{9}{8} \cdot \frac{E_{y z}}{E_{z z}} b^{\prime}(h) ; \\
& q_{3}=10 \cdot \frac{E_{y z}}{E_{z z}} b^{\prime}(h) ; \\
& q_{5}=-\frac{147}{8} \cdot \frac{E_{y z}}{E_{z z}} b^{\prime}(h) ; \\
& q_{7}=9 \cdot \frac{E_{y z}}{E_{z z}} b^{\prime}(h) ;
\end{aligned}
$$

-for $p(y)$ function

$$
\begin{aligned}
& p_{1}=\frac{9}{8} \cdot \frac{E_{y z}}{E_{z z}} b^{\prime}(h) ; \\
& p_{3}=-10 \cdot \frac{E_{y z}}{E_{z z}} b^{\prime}(h) ; \\
& p_{5}=\frac{147}{8} \cdot \frac{E_{y z}}{E_{z z}} b^{\prime}(h) ; \\
& p_{7}=-9 \cdot \frac{E_{y z}}{E_{z z}} b^{\prime}(h) ;
\end{aligned}
$$

-for $v(y)$ function

$$
\begin{aligned}
& v_{2}=\left[\frac{45}{16} \frac{E_{y z}}{E_{y y}}+\frac{105}{4} \cdot \frac{b^{2}}{h^{2}}\right] g(h) ; \\
& v_{4}=-\left[\frac{105}{16} \frac{E_{y z}}{E_{y y}}+\frac{525}{4} \cdot \frac{b^{2}}{h^{2}}\right] g(h) ; \\
& v_{6}=\left[\frac{63}{16} \frac{E_{y z}}{E_{y y}}+\frac{735}{4} \cdot \frac{b^{2}}{h^{2}}\right] g(h) ; \\
& v_{8}=-\frac{315}{4} \cdot \frac{b^{2}}{h^{2}} g(h) ;
\end{aligned}
$$

-for $g(y)$ function

$$
\begin{aligned}
& g_{1}=\left[-\frac{1575}{16} \cdot \frac{b^{2}}{h^{2}} \frac{E_{z y}}{E_{z z}}+\frac{3}{16} \cdot \frac{b^{2}}{h^{2}} \frac{E_{y z}}{E_{y y}}-\frac{105}{16}\right] g(h), \\
& g_{3}=\left[\frac{8190}{16} \cdot \frac{b^{2}}{h^{2}} \frac{E_{z y}}{E_{z z}}-\frac{15}{16} \cdot \frac{b^{2}}{h^{2}} \frac{E_{y z}}{E_{y y}}+\frac{385}{16}\right] g(h) ; \\
& g_{5}=\left[-\frac{11655}{16} \cdot \frac{b^{2}}{h^{2}} \frac{E_{z y}}{E_{z z}}+\frac{21}{16} \cdot \frac{b^{2}}{h^{2}} \frac{E_{y z}}{E_{y y}}-\frac{399}{16}\right] g(h) ; \\
& g_{7}=\left[\frac{5040}{16} \cdot \frac{b^{2}}{h^{2}} \frac{E_{z y}}{E_{z z}}-\frac{9}{16} \cdot \frac{b^{2}}{h^{2}} \frac{E_{y z}}{E_{y y}}+\frac{135}{16}\right] g(h) ;
\end{aligned}
$$

-for $f(y)$ function

$$
\begin{aligned}
& f_{1}=\left[\frac{1575}{16} \cdot \frac{b^{2}}{h^{2}} \frac{E_{z y}}{E_{z z}}-\frac{9}{16} \cdot \frac{b^{2}}{h^{2}} \frac{E_{y z}}{E_{y y}}+\frac{315}{16}\right] g(h) ; \\
& f_{3}=\left[-\frac{8190}{16} \cdot \frac{b^{2}}{h^{2}} \frac{E_{z y}}{E_{z z}}+\frac{45}{16} \cdot \frac{b^{2}}{h^{2}} \frac{E_{y z}}{E_{y y}}-\frac{1155}{16}\right] g(h) ; \\
& f_{5}=\left[\frac{11655}{16} \cdot \frac{b^{2}}{h^{2}} \frac{E_{z y}}{E_{z z}}-\frac{63}{16} \cdot \frac{b^{2}}{h^{2}} \frac{E_{y z}}{E_{y y}}+\frac{1197}{16}\right] g(h)=
\end{aligned}
$$




$$
f_{7}=\left[-\frac{5040}{16} \cdot \frac{b^{2}}{h^{2}} \frac{E_{z y}}{E_{z z}}+\frac{27}{16} \cdot \frac{b^{2}}{h^{2}} \frac{E_{y z}}{E_{y y}}-\frac{405}{16}\right] g(h) .
$$

For $u(y)$ function, the next function is considered:

$$
u(y)=\frac{u_{1}}{h} y+\frac{u_{3}}{h^{3}} y^{3},
$$

where:

$$
\begin{aligned}
& u_{1}=\frac{h}{2}(v(h)-3), \\
& u_{3}=-\frac{h}{2}(v(h)-1) .
\end{aligned}
$$
zero.

Because $p(y)+q(y)=0$ then also the $a(y)$ function is

In the Euler-Bernoulli theory case, the transversal vibrations equation is:

$$
\iint_{(S)} \ddot{w}_{y}(x, t) \cdot \rho d S+\frac{\partial^{2} M}{\partial x^{2}}=p_{y}
$$

where:

$-\rho$ is the bar material density; unit:

$p_{y}$ is the exterior loading which acts on the bar length

$-M$ is the bending moment and it is determined with the relation

It is obtained

$$
M=-\iint_{(S)} y \sigma_{x x} d S .
$$

$$
M=\langle E I\rangle w^{\prime \prime}(x, t),
$$

where:

$$
\langle E I\rangle=\frac{4 b h^{3}}{3}\left(1-\frac{9}{80} \frac{h^{2}}{b^{2}} \frac{E_{y z} E_{z y} E_{y z}}{E_{y y}\left(E_{y z} E_{z y}+2 E_{y y} E_{z z}\right)}\right) E_{x x} .
$$

Also

$$
\iint_{(S)} \ddot{w_{y}}(x, t) \cdot \rho d S=\langle\rho A\rangle \ddot{w}(x, t)
$$

where:

$$
\langle\rho A\rangle=4 \rho b h\left[1+\frac{E_{z y} E_{y z}}{E_{z y} E_{y z}+2 E_{y y} E_{z z}}\left(1+\frac{9 h^{2}}{16 b^{2}} \frac{E_{y z}}{E_{y y}}\right)\right] .
$$

If the transversal contraction factors are zero, there results:

$$
\begin{aligned}
& \langle E I\rangle=\frac{4 b h^{3}}{3} E, \\
& \langle\rho A\rangle=4 \rho b h,
\end{aligned}
$$

Like in the classical Euler-Bernoulli theory.

With $\langle E I\rangle$ and $\langle\rho A\rangle$ previously inserted, the transversal vibrations equation has the form:

$$
\langle\rho A\rangle \ddot{\psi}(x, t)+\langle E I\rangle w^{\prime \prime \prime}(x, t)=p_{y},
$$

which is identical with the classical equation EulerBernoulli for the bars transversal vibrations study. In the cause of damping presence, an extra term appears, which depends on the daping type [27], and the free vibrations have the form:

$$
w(x, t)=\sum_{n} W_{n}(x) e^{-\mu_{n} t} \sin \left(\sqrt{\omega_{n}^{2}-\mu_{n}^{2}} t+\varphi_{n}\right)
$$

in which $\mu_{n}$ is the damping factor for the $n$ vibration mode, and $W_{n}(x)^{n}$ are the eigenfunctions. These depend on the bar supporting conditions.
The eigenpulsations serios is given by the relation:

$$
\omega_{n}=\frac{\beta_{n}^{2}}{l^{2}} \sqrt{\frac{\langle E I\rangle}{\langle\rho A\rangle}},
$$

in which $\beta$ depend on the bar end conditions. By taking into account the transversal contraction factors shows that the eigenpulsations have smaller values than if these were neglected. Beucase, for a given value of the bar thickness, at the length increase, the $\langle E \mid\rangle$ term increased and $\langle\rho A\rangle$ term decreases and there results an increase of the eigenpulsations with the bar width increase.

\section{Experimental part}

We have made samples that are natural resin Dammar based. The composite materials based on this resin have a very long hardening time. To remove this shortcoming, we have used a small ratio of synthetic resin. More precisely, we have used $75 \%$ Dammar and $25 \%$ epoxy resin. The samples sets have densities between . The elastic and strength properties of this resin are given in [25]. From this resin type we have made for sets of composite materials by reinforcind them with flax, cotton, silk and hemp. We have made samples from this combined resin which was reinforced with:

- a mixed fabric from $40 \%$ cotton and $60 \%$ flax, with the specific mass of $240 \mathrm{~g} / \mathrm{m}^{2}$. We have used 12 layers, the obtained composite has the resin masic ratio of 0.52 and $1.21 \mathrm{~g} / \mathrm{cm}^{3}$ density;

- a mixed fabric from $60 \%$ silk and $40 \%$ cotton, with the specific mass of $162 \mathrm{~g} / \mathrm{m}^{2}$. We have used 20 layers, the obtained composite has the resin masic ratio of 0.51 and $1.16 \mathrm{~g} / \mathrm{cm}^{3}$ density;

-cotton fabric, with the specific mass of $126 \mathrm{~g} / \mathrm{m}^{2}$. We have used 24 layers, the obtained composite has the resin masic ratio of 0.50 and $1.18 \mathrm{~g} / \mathrm{cm}^{3}$ density;

- hemp fabric, with the specific mass of $353 \mathrm{~g} / \mathrm{m}^{2}$. We have used 6 layers, the obtained composite has the resin masic ratio of 0.62 and $1.10 \mathrm{~g} / \mathrm{cm}^{3}$ density.

The elastic and strength properties for these materials can be found in [25]. We have experimentally determined the damping factor for these samples sets. The studied samples had the length of $200 \mathrm{~mm}$ and widths of $10 \mathrm{~mm}$, $15 \mathrm{~mm}$ and $20 \mathrm{~mm}$ and were clamped at one end, and the vibration measurement was made at the free end. The free length for each studied bar was 100, 120, 140,160 and $180 \mathrm{~mm}$.

The used measuring apparatus was:

-accelerometer with the $0.04 \mathrm{pC} / \mathrm{ms}^{-2}$ sensitivity; -data acquisition system SPIDER 8;

-signal conditioner NEXUS 2692-A-014 connected to the SPIDER 8 system.

The data acquisition set was made with the CATMAN EASY software, and the frequency measuring field was between $0-2.400 \mathrm{~Hz}$ from SPIDER 8.

In the figure 2, the experimental recording of the vibration for the sample reinforced with hemp, having the with of $20 \mathrm{~mm}$ and the free length of $180 \mathrm{~mm}$. There is chosen this recording because it is the one where it was obtained the highest vibration frequency.

In the figure 3 there is presented the way of determining the damping factor from the recording presented in figure 2. The damping factor per unit was determined by using the same method from [16].

In the tables 1-4 the damping factor and eigenfrequency values are given, measured experimentally, for the four sample sets. 


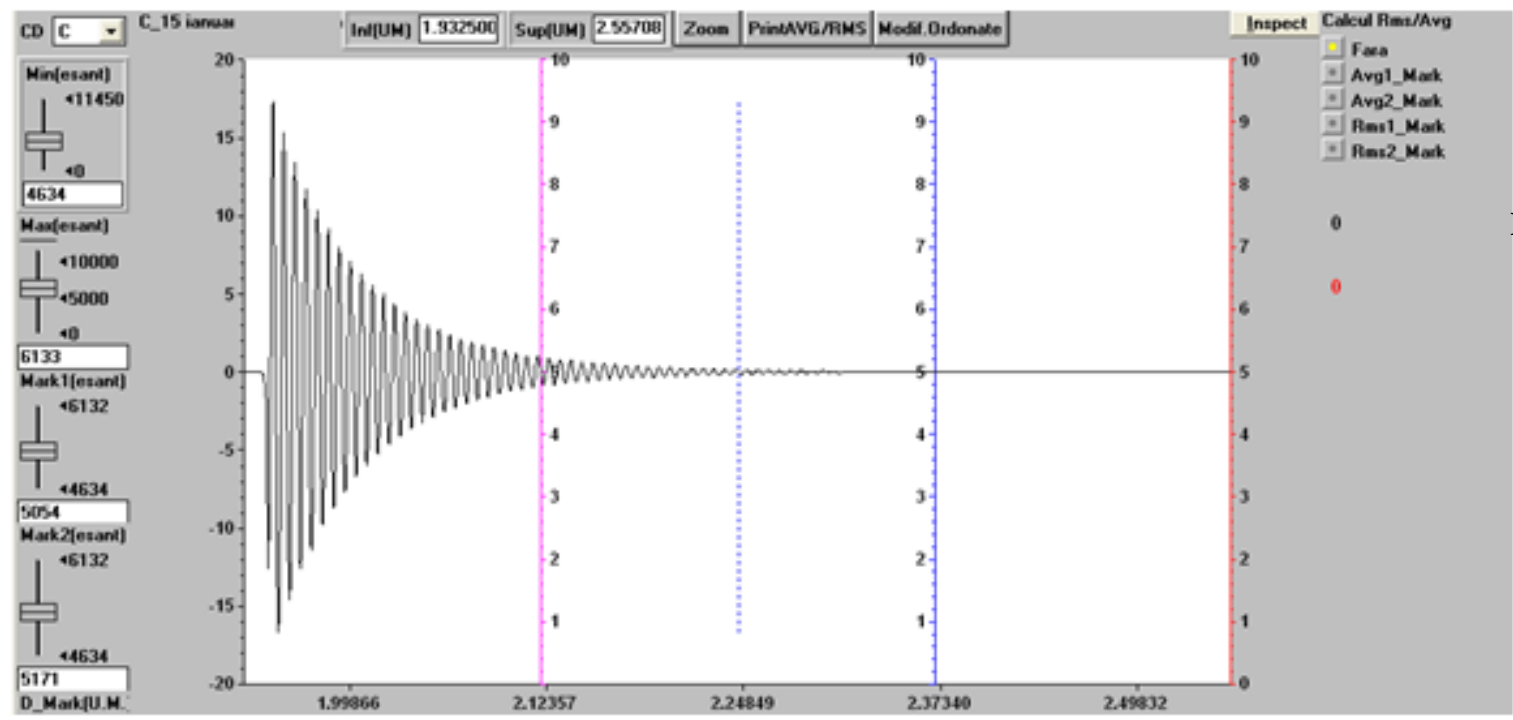

Fig. 2 Experimental recording of the vibration for the sample reinforced with hemp, $20 \mathrm{~mm}$ width and $100 \mathrm{~mm}$ free length

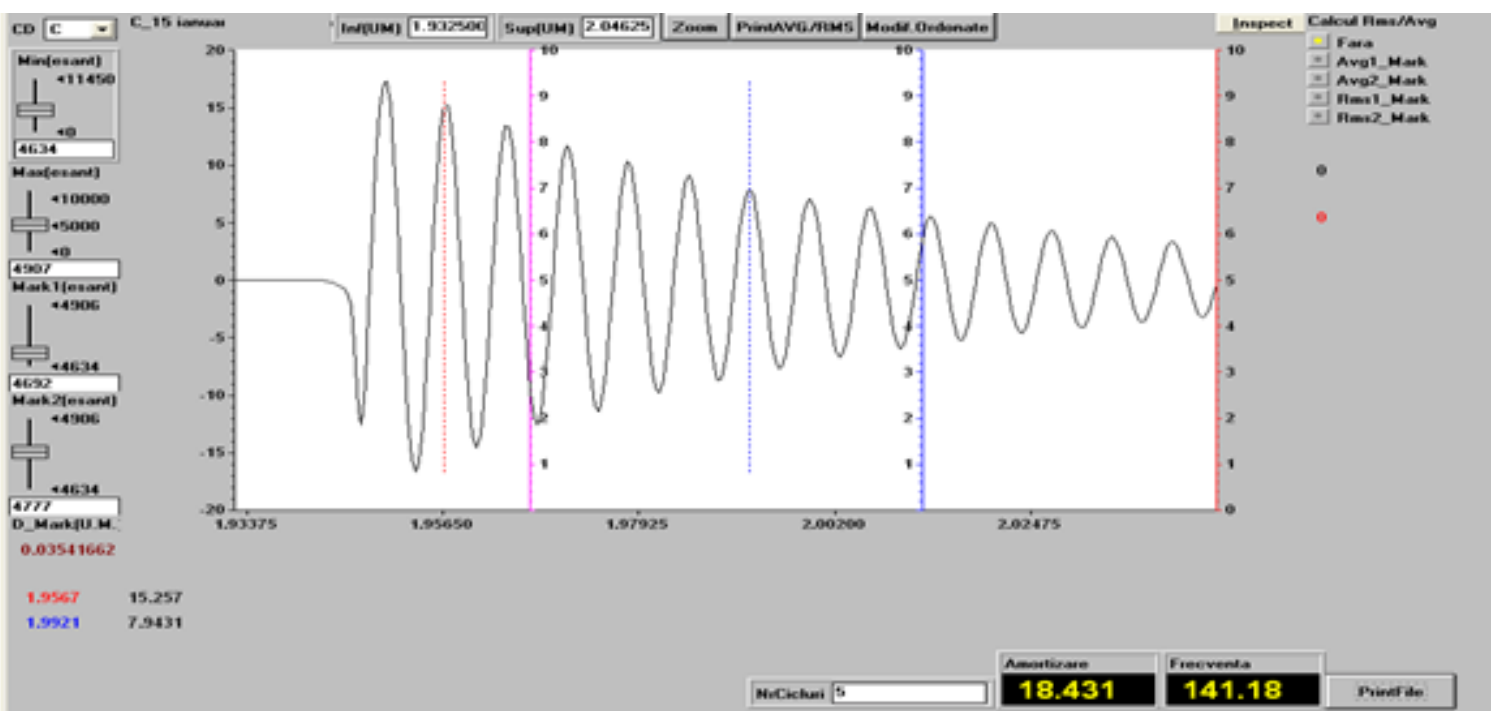

Fig. 3 Determining the damping factor for the sample reinforced with hemp, $20 \mathrm{~mm}$ width and $100 \mathrm{~mm}$ free length

\begin{tabular}{|c|c|c|c|c|c|c|}
\hline \multirow{2}{*}{ Width } & \multicolumn{2}{|c|}{$10 \mathrm{~mm}$} & \multicolumn{2}{c|}{$15 \mathrm{~mm}$} & \multicolumn{2}{c|}{$20 \mathrm{~mm}$} \\
\cline { 2 - 6 } & $\begin{array}{c}\text { Damping } \\
\text { factor }\left[\mathrm{s}^{-1}\right]\end{array}$ & $\begin{array}{c}\text { Frequency } \\
{[\mathrm{Hz}]}\end{array}$ & $\begin{array}{c}\text { Damping } \\
\text { factor }\left[\mathrm{s}^{-1}\right]\end{array}$ & $\begin{array}{c}\text { Frequency } \\
{[\mathrm{Hz}]}\end{array}$ & $\begin{array}{c}\text { Damping } \\
\text { factor }\left[\mathrm{s}^{-1}\right]\end{array}$ & $\begin{array}{c}\text { Frequency } \\
{[\mathrm{Hz}]}\end{array}$ \\
\hline $100 \mathrm{~mm}$ & 23.99 & 81.35 & 21.24 & 91.25 & 21.16 & 96.38 \\
\hline $120 \mathrm{~mm}$ & 15.76 & 58.25 & 16.99 & 65.04 & 17.98 & 70.37 \\
\hline $140 \mathrm{~mm}$ & 12.33 & 43.02 & 13.89 & 51.28 & 13.77 & 54.05 \\
\hline $160 \mathrm{~mm}$ & 9.54 & 34.04 & 9.74 & 40.61 & 11.28 & 41.73 \\
\hline $180 \mathrm{~mm}$ & 7.57 & 28.80 & 8.88 & 31.29 & 9.39 & 34.08 \\
\hline
\end{tabular}

Table 1

THEDAMPING

FACTOR AND FREQENCY FOR THE SAMPLES REINFORCED WITH COTTON

\begin{tabular}{|c|c|c|c|c|c|c|}
\hline \multirow{2}{*}{ Width } & \multicolumn{2}{|c|}{$10 \mathrm{~mm}$} & \multicolumn{2}{c|}{$15 \mathrm{~mm}$} & \multicolumn{2}{c|}{$20 \mathrm{~mm}$} \\
\cline { 2 - 7 } & $\begin{array}{c}\text { Damping } \\
\text { factor }\left[\mathrm{s}^{-1}\right]\end{array}$ & $\begin{array}{c}\text { Frequency } \\
{[\mathrm{Hz}]}\end{array}$ & $\begin{array}{c}\text { Damping } \\
\text { factor }\left[\mathrm{s}^{-1}\right]\end{array}$ & $\begin{array}{c}\text { Damping } \\
\text { factor }\left[\mathrm{s}^{-1}\right]\end{array}$ & $\begin{array}{c}\text { Frequency } \\
{[\mathrm{Hz}]}\end{array}$ \\
\hline $100 \mathrm{~mm}$ & 25.43 & 112.15 & 30.33 & 118.81 & 34.19 & 122.45 \\
\hline $120 \mathrm{~mm}$ & 18.87 & 81.63 & 22.83 & 87.59 & 26.06 & 89.55 \\
\hline $140 \mathrm{~mm}$ & 14.29 & 61.38 & 17.60 & 67.79 & 21.94 & 70.18 \\
\hline $160 \mathrm{~mm}$ & 10.55 & 46.87 & 13.19 & 50.20 & 15.61 & 53.81 \\
\hline $180 \mathrm{~mm}$ & 8.77 & 38.09 & 9.98 & 40.13 & 11.87 & 42.40 \\
\hline
\end{tabular}

\begin{tabular}{|c|c|c|c|c|c|c|}
\hline \multirow[b]{2}{*}{ Length } & \multicolumn{2}{|c|}{$10 \mathrm{~mm}$} & \multicolumn{2}{|c|}{$15 \mathrm{~mm}$} & \multicolumn{2}{|c|}{$20 \mathrm{~mm}$} \\
\hline & $\begin{array}{l}\text { Damping } \\
\text { factor }\left[\mathrm{s}^{-1}\right]\end{array}$ & $\begin{array}{c}\text { Frequency } \\
{[\mathrm{Hz}]}\end{array}$ & $\begin{array}{l}\text { Damping } \\
\text { factor }\left[\mathrm{s}^{-1}\right]\end{array}$ & & $\begin{array}{l}\text { Damping } \\
\text { factor }\left[\mathrm{s}^{-1}\right]\end{array}$ & $\begin{array}{c}\text { Frequency } \\
{[\mathrm{Hz}]}\end{array}$ \\
\hline $100 \mathrm{~mm}$ & 31.31 & 77.41 & 27.96 & 87.59 & 27.37 & 90.56 \\
\hline $120 \mathrm{~mm}$ & 22.50 & 55.81 & 24.36 & 63.49 & 23.78 & 65.22 \\
\hline $140 \mathrm{~mm}$ & 17.25 & 44.11 & 20.61 & 47.81 & 19.48 & 49.58 \\
\hline $160 \mathrm{~mm}$ & 13.61 & 33.70 & 16.18 & 37.04 & 16.59 & 38.21 \\
\hline $180 \mathrm{~mm}$ & 10.31 & 27.33 & 11.26 & 29.02 & 13.71 & 31.33 \\
\hline
\end{tabular}

THEDAMPING

FACTOR AND

REQENCY FOR THE

SAMPLES

REINFORCED WITH

SILK

THE DAMPING

FACTOR AND REQENCY FOR THE SAMPLES FLAX 
Tabelul 4

THE DAMPING FACTOR AND FREQENCY FOR THE SAMPLES REINFORCED WITH HEMP

\begin{tabular}{|c|c|c|c|c|c|c|}
\hline \multirow{2}{*}{ Wength } & \multicolumn{2}{|c|}{$10 \mathrm{~mm}$} & \multicolumn{2}{c|}{$15 \mathrm{~mm}$} & \multicolumn{2}{c|}{$20 \mathrm{~mm}$} \\
\cline { 2 - 7 } & $\begin{array}{c}\text { Damping } \\
\text { factor }\left[\mathrm{s}^{-1}\right]\end{array}$ & $\begin{array}{c}\text { Frequency } \\
{[\mathrm{Hz}]}\end{array}$ & $\begin{array}{c}\text { Damping } \\
\text { factor }\left[\mathrm{s}^{-1}\right]\end{array}$ & $\begin{array}{c}\text { Damping } \\
\text { factor }\left[\mathrm{s}^{-1}\right]\end{array}$ & $\begin{array}{c}\text { Frequency } \\
{[\mathrm{Hz}]}\end{array}$ \\
\hline $100 \mathrm{~mm}$ & 24.34 & 121.21 & 20.42 & 136.36 & 18.43 & 141.18 \\
\hline $120 \mathrm{~mm}$ & 18.16 & 89.22 & 17.11 & 100.84 & 15.85 & 103.56 \\
\hline $140 \mathrm{~mm}$ & 15.19 & 68.18 & 12.71 & 75.47 & 12.06 & 78.94 \\
\hline $160 \mathrm{~mm}$ & 11.14 & 51.61 & 9.39 & 57.69 & 9.76 & 60.91 \\
\hline $180 \mathrm{~mm}$ & 8.45 & 42.41 & 8.18 & 45.62 & 8.51 & 50.63 \\
\hline
\end{tabular}

\section{Conclusions}

In the case of classical models, Euler-Bernoulli and Timoshenko, used for the bars vibrations study, the influence of the transversal contraction factors is nottaken into account. That is why, in the case of bars with rectangular section the displacements of the bar points do not depend on its width. Also, all the points from a section have the same stransversal displacement, and the longitudinal displacement is symmetrical toward the median plane. Thereupon, the vibration parameters are not infleunced by the bar width.

The presented theory is based on an assymetric distribution of strains toward the medium plane, the area loaded to compression has a transversal expansion, and the area tensile loaded is straiten. Thereupon, the points from a ber section will not have the same transversal displacement. The results an increase of the eigenpulsations with the bar width increase. This increase was experimentally verified at four composite bars with natural resin Dammar based matrix, reinforced with fibers made of cotton, flax, silk and hemp.

For the bars reinforced with flax, the frequency mean increase was of $14 \%$ for the bar with $15 \mathrm{~mm}$ width and $18 \%$ for the bar with $20 \mathrm{~mm}$ width. For the bars reinforced with cotton, the frequency mean increase was of $8 \%$ for the bar with $15 \mathrm{~mm}$ width and of 12\% for the bar with 20 $\mathrm{mm}$ width. For the bars reinforced with silk, the frequency mean increase was of $10 \%$ for the bar with $15 \mathrm{~mm}$ width and of $15 \%$ for the bar with $20 \mathrm{~mm}$ width. For the bars reinforced with hemp, the frequency mean increase was of $11 \%$ for the bar with $15 \mathrm{~mm}$ width and of $17 \%$ for the bar with $20 \mathrm{~mm}$ width.

A conclusion regarding the influence of the bar width over the damping properties cannot be extracted. So, in the case of samples reinforced with cotton, a slightly increase of the damping factor depending on the bar length was observed, but for the bars reinforced with hemp the phenomenon was opposite, the damping factor decreases with the bar width. Moreover, at the samples reinforced with silk, at the bars with $100 \mathrm{~mm}$ free length, the damping factor decreased with the bar width, while at the bars with the free length of $180 \mathrm{~mm}$, the damping factor increased with the bar width. At the bars reinforced with flax, the phenomenon was opposite.

\section{References}

1.YANG, P.C., NORRIS, C.H., STAVSKY, Y., Elastic wave propagation in heterogeneous plates, International J ournal of Solids and Structures, 2(4), 1966, p. 665-684.

2.WHITNEY, J.M., PAGANO, N.Y.S., Shear deformation in heterogeneous anisotropic plates, J. Appl. Mech., 37(4), 1970, p. 1031-1036.

3.TIMOSHENKO, S.P., On the correction for shear of the differential equation for transverse vibrations of prismatic bars, Philosophical Magazine, 41(6), 1921, p. 742-746.

4.AKAVCI, S.S., Buckling and free vibration analysis of symmetric and anti-symmetric laminated composite plates on an elastic foundation,
Journal of Reinforced Plastics and Composites, 26 (18), 2007, p. 19071919.

5.AMBARTSUMYAN, S.A., On the theory of bending plates, Izv Otd Tech Nauk AN SSSR, 5, 1958, p. 69-77.

6.KARAMA, M., AFAQ, K.S., MISTOU, S., Mechanical behavior of laminated composite beam by new multi-layered laminated composite structures model with transverse shear stress continuity, International J ournal of Solids and Structures, 40, 2003, p. 1525-1546.

7.REDDY, J.N., A general non-linear third order theory of plates with moderate thickness, International Journal of Non-linear Mechanics, 25 (6), 1990, p. 677-686.

8.SOLDATOS, K.P., A transverse shear deformation theory for homogeneous monoclinic plates, Acta Mechanica, 94, 1992, p. 195200.

9.TOURATIER, M., An efficient standard plate theory, International J ournal of Engineering Science, 29(8), 1991, p. 901-916.

10.SAYYAD, A.S., Comparison of various refined beam theories for the bending and free vibration analysis of thick beams, Applied and Computational Mechanics, 5, 2011, p. 217-230.

11.STEIN, M., Vibration of beams and plate strips with threedimensional flexibility, Transaction ASME J ournal of Applied Mechanics, 56 (1), 1989, p. 228-231.

12.GHUGAL, Y.M., SHARMA, R., Hyperbolic shear deformation theory for flexure and vibration of thick isotropic beams, International J ournal of Computational Methods, 6 (4), 2009, p. 585-604.

13.GHUGAL, Y.M., SHIMPI, R.P., A review of refined shear deformation theories for isotropic and anisotropic laminated beams, Journal of Reinforced Plastics and Composites, 21, 2002, p. 775-813.

14.BOLCU, D., STANESCU, M.M., CIUCA, I., DUMITRU, S., SAVA, M., The Non-uniformity from the composite materials reinforced with fiber glass fabric, Mat. Plast., 51, no. 1, 2014, p. 97

15.STANESCU, M.M., BOLCU, D., MANEA, I., CIUCA, I., BAYER, M., SEMENESCU, A., Experimental researches concerning the properties of composite materials with random distribution of reinforcement, Mat. Plast., 46, no. 1, 2009, p. 73

16.BOLCU, D., STANESCU, M.M., CIUCA, I., MIRITOIU, C., BOLCU., AL., CIOCOIU, R., The vibration study of Dammar based composite bars by using a new Euler-Bernoulli Theory, Mat. Plast., 54, no. 1, 2017, p. 1

17.MOHANTY, A.K., MISRA, M., HINRICHSEN, G., Biofibers, biodegradable polymers and biocomposites: an overview, Macromol. Mater. Eng., 276-277, 2000, p. 1-24.

18.DHAKAL, H.N., ZHANG, Z.Y., RICARDSON, M.O.W., Effect of water absorption on the mechanical properties of hemp fibre reinforced unsaturated polyester composites, Compos. Sci. Technol., 67, 2007, p. 1674-1683.

19.AHMAD, I., BAHARUM, A., ABDULLAH, I., Effect of extrusion rate and fiber loading on mechanical properties of Twaron fiberthermoplastic natural rubber (TPNR) composites, J. Reinf. Plast. Compos., 25, 2006, p. 957-965.

20.KU, H., WANG, H., PATTARACHAIYAKOOP, N., TRADA, M., A review on the tensile properties of natural fibre reinforced polymer composite, Compos. Part B-Engineering, 42, 2011, p. 856-873.

21.KORONIS, G., SILVA, A., FONTUL, M., Green composites: A review of adequate materials for automotive apllications, Compos. Part BEngineering, 44, 2013, p. 120-127. 
22.KABIR, M.M., WANG, H., LAU, K.T., CARDONA, F., Chemical treatments on plant-based natural fibre reinforced polimer composite: An overview, Compos. Part B-Engineering, 43, 2012, p. 2883-2892. 23.MEI-PO, H., WANG, H., JOONG-HEE, L., KIN-TAK, L., JINSONG, L., HUI, D., Critical factors on manufacturing processes of natural fibre composites, Compos. Part B-Engineering, 43, 2012, p. 3549-3562.

24.HOI-YAN, C., MEI-PO, H., KIN-TAK, L., CARDONA, F., HUI, D., Natural fibre-reinforced composites for bioengineering an enviromental engineering applications, Compos. Part B-Engineering, 40, 2009, p. $655-663$.
25.STANESCU, M.M., Study regarding the mechanical behaviour of Dammar based composite materials, reinforced with natural fiber fabrics. Mat. Plast., 52, no. 4, 2015, p. 596

26.TARNITA, D., Wearable sensors used for human gait analysis, Rom J Morphol Embryo/ 2016, 57(2), p. 373-382.

27.HERRMANN L., Vibration of the Euler-Bernoulli beam with allowance for dampings, Proceedings of the World Congress on Engineering 2008 Vol II ,WCE 2008, July 2 - 4, 2008, London, U.K.

$\overline{\text { Manuscript received: 21.03.2017 }}$ 